\title{
In quella parte del libro de la mia memoria. Verità e finzioni dell'»io» autobiografico, a cura di Francesco Bruni
}

\section{Fatima Pilone}

\section{(2) OpenEdition}

1 Journals

\section{Edizione digitale}

URL: https://journals.openedition.org/studifrancesi/41480

DOI: $10.4000 /$ studifrancesi. 41480

ISSN: 2421-5856

\section{Editore}

Rosenberg \& Sellier

\section{Edizione cartacea}

Data di pubblicazione: 1 juillet 2004

Paginazione: 246

ISSN: 0039-2944

\section{Notizia bibliografica digitale}

Fatima Pilone, «In quella parte del libro de la mia memoria. Verità e finzioni dell'»io» autobiografico, a cura di Francesco Bruni», Studi Francesi [Online], 142 (XLVIII | I) | 2004, online dal 30 novembre 2015, consultato il 09 septembre 2021. URL: http://journals.openedition.org/studifrancesi/41480 ; DOI: https://doi.org/10.4000/studifrancesi.41480

Questo documento è stato generato automaticamente il 9 septembre 2021.

\section{cc) $(8)$}

Studi Francesi è distribuita con Licenza Creative Commons Attribuzione - Non commerciale - Non opere derivate 4.0 Internazionale. 


\title{
In quella parte del libro de la mia memoria. Verità e finzioni dell' "io» autobiografico, a cura di Francesco Bruni
}

\author{
Fatima Pilone
}

\section{NOTIZIA}

AA.VV., In quella parte del libro de la mia memoria. Verità e finzioni dell'»io» autobiografico, a cura di Francesco BRUNI, Padova, Marsilio, 2003, (coll. Fondazione Giorgio Cini), pp. 495.

1 Il titolo di questa miscellanea a cura di Francesco Bruni ci proietta immediatamente in un preciso settore della scrittura di tipo memorialistico: il mondo dell'io autobiografico, in un contesto prettamente letterario ma non solo. Questo genere di scrittura, infatti, apre spesso dibattiti che si nutrono anche di principi tipici di altre discipline, come la filosofia, la storia, l'antropologia e, considerando l'evoluzione del genere a partire dalla fine del XIX secolo, la psicologia.

2 L'autobiografia come genere letterario è sicuramente un fenomeno caratteristico dell'età moderna mentre la pulsione a parlare di sé è ben più antica, tanto quanto lo è l'uomo: dall'antichità all'odierna società mediatica, l'uomo ha infatti scritto il libro della propria memoria, dalla forma epistolare a quella diaristica, dalle memorie all'autobiografia vera e propria.

3 In un'ossessiva esibizione dell'io, il lavoro di Francesco Bruni, professore di lingua italiana a Venezia, mette insieme una serie di saggi relativi ad opere di impianto autobiografico dichiarato: dalle Confessioni di Agostino alla Vita nova di Dante; dalle riflessioni politiche di Guicciardini all'autobiografia di Cellini; e poi ancora Alfieri, Foscolo, Leopardi, d'Azeglio, Saba, fino ad arrivare allo specchio della memoria di Levi. In un'appendice, il fenomeno viene studiato in relazione agli ultimi eventi storici e 
politici, per esempio inserendolo nel contesto dell'Unione Europea; inoltre, un'intervista a Sebastiano Vassalli, offre lo spunto per analizzare il genere dell'autobiografia attraverso gli scrittori contemporanei.

4 Per quanto riguarda la letteratura francese, il libro propone un saggio di Lucia Omacini su Jean-Jacques Rousseau e la sua «impresa che non conosce esempi»: le Confessioni. L'opera di Rousseau segna un momento fondamentale nell'evoluzione dell'autobiografia: innanzitutto, apre definitivamente la scrittura al mondo dell'io, ai piaceri dell'introspezione, del ricordo, del sogno e della meditazione, anticipando il Romanticismo; ed inoltre, sancisce il passaggio ad un nuovo rapporto con il lettore, con il quale viene instaurato il "patto autobiografico» tanto studiato da Philippe Lejeune. Da una parte, dunque, Rousseau inserisce il genere in una più ampia dimensione psicologica; dall'altra, affida al lettore il compito di mettere insieme i tasselli di un mosaico complesso, quello della sua stessa vita, raccontata attraverso la propria voce, o meglio, la propria mano.

5 L'idea delle Confessioni nasce non tanto con un fine artistico ma con l'intento di fare una personale arringa difensiva. Rousseau si sentiva vittima di pregiudizi sociali: Èmile e Le contrat social erano stati causa di un arresto e della conseguente fuga in Svizzera, e lo scrittore sentiva il bisogno di mostrare quanto fosse sbagliata l'immagine di uomo che veniva additato come malvagio alla pubblica riprovazione. Anche l'incipit, pensato tra il 1766 ed il 1769, era la risposta a un attacco di Voltaire del 1765 che con le Sentiment des citoyens lo accusava di aver abbandonato i figli, confermando quindi l'idea di un personaggio negativo. Le Confessioni di Rousseau si collocano sul piano umano e non, come quelle di Agostino, sul piano religioso. Egli vuole mostrarsi in tutta la sua verità, in un processo di riconoscirnento dell'uomo puro, essenziale, tornato allo stato di natura attraverso il «sentire», senza preoccuparsi dello stile, perché è l'emozione stessa che si fa linguaggio, secondo il principio di verità della parola. 